Progress Report, WSU 2005

\title{
CHARACTERIZATION OF ACTINIDES IN SIMULATED ALKALINE TANK WASTE SLUDGES AND LEACHATES
}

\section{Project ID number 81940}

\begin{tabular}{|c|c|c|}
\hline Principal Investigator: & \multicolumn{2}{|c|}{$\begin{array}{l}\text { Kenneth L. Nash } \\
\text { Chemistry Department } \\
\text { Washington State University } \\
\text { Pullman, WA 99164 } \\
\text { (tel) 509-335-2654, (fax) 509-335-8867 } \\
\text { e-mail: knash@mail.wsu.edu) }\end{array}$} \\
\hline Co-Investigator: & \multicolumn{2}{|c|}{$\begin{array}{l}\text { Linfeng Rao } \\
\text { Lawrence Berkeley National Laboratory } \\
\text { (tel) 510-486-5427, (fax) 510-486-5596 } \\
\text { e-mail: LRao@lbl.gov }\end{array}$} \\
\hline \multirow{3}{*}{$\begin{array}{l}\text { Research } \\
\text { Personnel }\end{array}$} & Leigh Martin & Postdoctoral \\
\hline & $\begin{array}{c}\text { Ryan } \\
\text { Harrington }\end{array}$ & Graduate Student \\
\hline & $\begin{array}{l}\text { Amanda Routt } \\
\text { Jim Neeway } \\
\text { Ryan Witty }\end{array}$ & $\begin{array}{l}\text { Undergraduate } \\
\text { Students }\end{array}$ \\
\hline LBNL & $\begin{array}{l}\text { Brian A. Powell } \\
\text { Wendy A. Reed }\end{array}$ & $\begin{array}{l}\text { Postdoctoral } \\
\text { Postdoctoral }\end{array}$ \\
\hline
\end{tabular}

\section{RESEARCH OBJECTIVES}

Removal of waste-limiting components of sludge ( $\mathrm{Al}, \mathrm{Cr}, \mathrm{S}, \mathrm{P}$ ) in underground tanks at Hanford by treatment with concentrated alkali has proven less efficacious for $\mathrm{Al}$ and $\mathrm{Cr}$ removal than had been hoped. More aggressive treatments of sludges, for example, contact with oxidants targeting $\mathrm{Cr}(\mathrm{III})$, have been tested in a limited number of samples and found to improve leaching efficiency for Cr. Oxidative alkaline leaching can be expected to have at best a secondary influence on the mobilization of Al. Our earlier explorations of $\mathrm{Al}$ leaching from sludge simulants indicated acidic and complexometric leaching can improve Al dissolution. 
Unfortunately, treatments of sludge samples with oxidative alkaline, acidic or complexing leachates produce conditions under which normally insoluble actinide ions (e.g., $\mathrm{Am}^{3+}, \mathrm{Pu}^{4+}$, $\mathrm{Np}^{4+}$ ) can be mobilized to the solution phase. Few experimental or meaningful theoretical studies of actinide chemistry in strongly alkaline, strongly oxidizing solutions have been completed. Unfortunately, extrapolation of the more abundant acid phase thermodynamic data to these radically different conditions provides limited reliable guidance for predicting actinide speciation in highly salted alkaline solutions. In this project, we are investigating the fundamental chemistry of actinides and important sludge components in sludge simulants and supernatants under representative oxidative leaching conditions. We are examining the potential impact of acidic or complexometric leaching with concurrent secondary separations on $\mathrm{Al}$ removal from sludges. Finally, a portion of our research is directed at the control of polyvalent anions $\left(\mathrm{SO}_{4}{ }^{=}, \mathrm{CrO}_{4}{ }^{=}\right.$, $\mathrm{PO}_{4}{ }^{3-}$ ) in waste streams destined for vitrification. Our primary objective is to provide adequate insight into actinide behavior under these conditions to enable prudent decision making as tank waste treatment protocols develop. We expect to identify those components of sludges that are likely to be problematic in the application of oxidative, acidic, and complexometric leaching protocols.

\section{RESEARCH PROGRESS AND IMPLICATIONS}

This report summarizes work for FY05 (10/1/2004 - 9/30/2005)

\section{Complexation of U(VI) with 1-Hydroxyethane-1,1-diphosphonic Acid (HEDPA) in Acidic and Basic Solutions.}

Thermodynamics. To support possible utilization of the complexants like HEDPA for applications in tank waste cleanup, sludge dissolution, and residue stabilization, we have extended the thermodynamic studies of the complexation of actinides with HEDPA from acidic to neutral and basic solutions. A combination of characterization techniques, including potentiometry, calorimetry, NMR, ES-MS and optical spectroscopies, has been used in this study. Integration of the information obtained by multiple techniques has provided valuable information on the complex species and the competition between the ligand and $\mathrm{OH}^{-}$. Information on the ligand/ $\mathrm{OH}^{-}$competition is of great importance in evaluating the efficacy of the ligand in alkaline washing of the tank sludges.

Multiple $\mathrm{M}_{m} \mathrm{H}_{h} \mathrm{~L}_{l}$ complexes across the $\mathrm{pH}$ 2-12 region have been identified by potentiometric $(\mathrm{pH})$ and spectrophotometric titrations, combined with ${ }^{31} \mathrm{P}$ NMR spectroscopy and ES-MS experiments. A representative speciation diagram (pH 2-12) is shown in Figure 1. Small amounts of dinuclear complexes also form in neutral to basic solutions, but these are insignificant when the $\left[\right.$ HEDPA]/[U] ratio is above 2. Preliminary analysis of the data from ${ }^{31} \mathrm{P}$ NMR spectroscopy and ES-MS experiments confirms the existence of the major U/HEDPA species. 


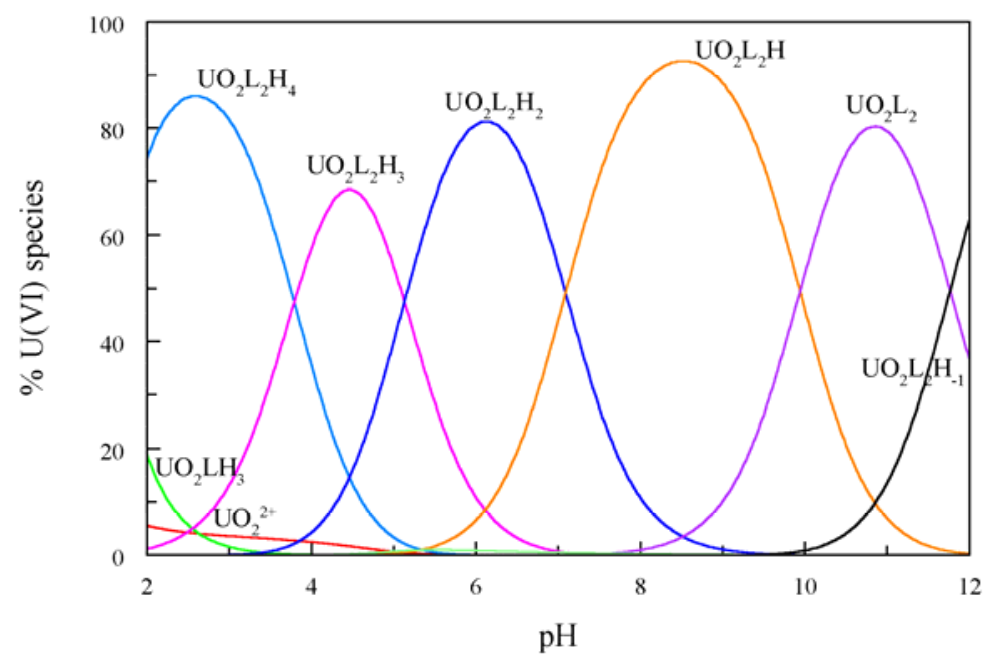

Figure 1: Speciation of $U(V I)$ in the presence of HEDPA. $[U]=0.005 \mathrm{M}$; [HEDPA] $=0.01$ M. L stands for HEDPA ${ }^{4-}$.

Kinetics. The rate of complexation between $\mathrm{UO}_{2}{ }^{2+}$ and a few related diphosphonic acids, including HEDPA, VDPA (vinylidene-1,1-diphosphonic acid) and BZDPA (benzene-1,2diphosphonic acid), was studied by stopped-flow absorption spectroscopy, using chlorophosphonazo III (CLIII) as the competing agent. Figure 2a shows the absorption spectra collected within 4 seconds of mixing a solution of U(VI)/CLIII and a solution of HEDPA. The peaks at 620 and $670 \mathrm{~nm}$ are due to the $\mathrm{U}(\mathrm{VI}) / \mathrm{CLIII}$ complex while the broad bands at 520-570 $\mathrm{nm}$ are due to the free CLIII ligand. Upon mixing with HEDPA, the CLIII was freed due to the formation of U(VI)/HEDPA complexes. Figure $2 \mathrm{~b}$ shows a kinetic trace at $610 \mathrm{~nm}$. The stoppedflow experiments have been conducted at different $\mathrm{pH}$ and reactant concentrations. Global analysis of the sets of spectra as shown in Figure 2a generates the rate constants of the reaction and helps to reveal the reaction mechanism. Preliminary analysis of the data indicates that the reaction rate of $\mathrm{U}(\mathrm{VI})$ complexation with a few related diphosphonic acids follows the order: HEDPA > VDPA > BZDPA, which could be rationalized by the ligand rigidity and steric effect on the formation of $\mathrm{U}(\mathrm{VI})$ complexes. 


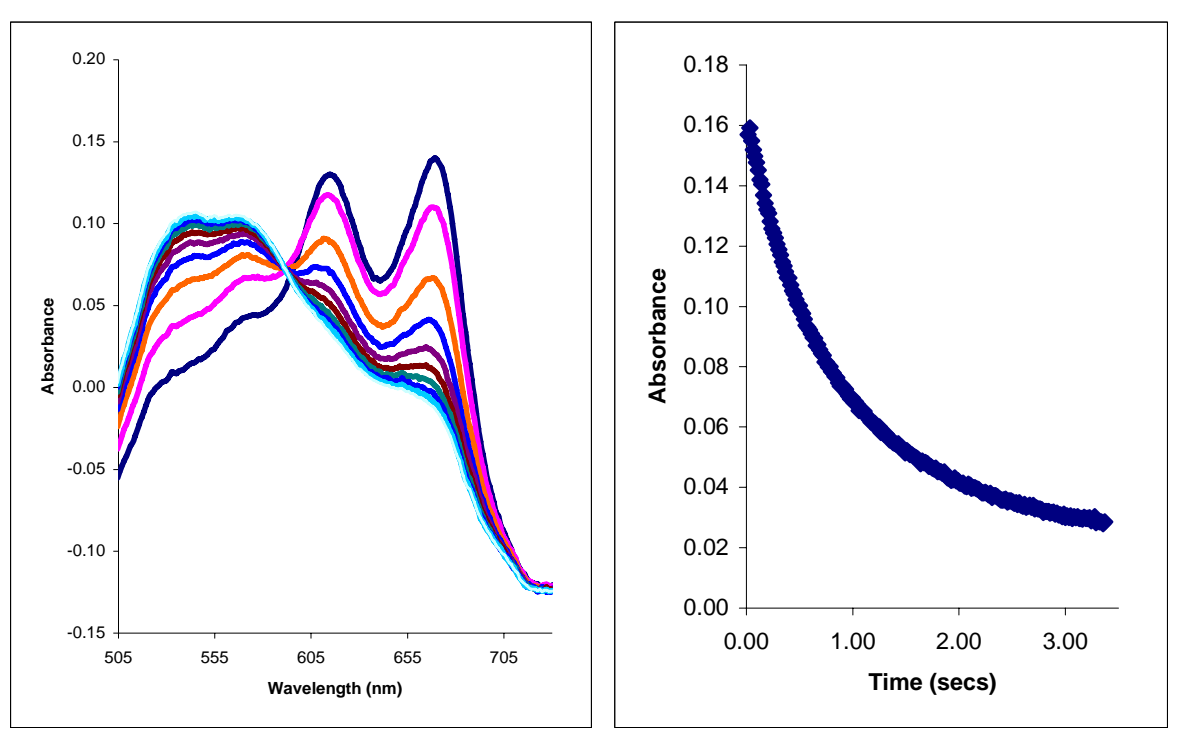

Figure 2: Stopped-flow absorption spectroscopy. [U(VI)/CLIII] $=0.00001 \mathrm{M} ; \mathrm{pH}=2$; $[H E D P A]=0.005 M$. (a) Absorption spectra at different time after mixing $\left(t_{\max }=4\right.$ seconds); (b) kinetic trace at $610 \mathrm{~nm}$.

\section{Effect of HEDPA on the Sorption of Actinides on $\gamma$-alumina.}

The nuclear waste sludges in underground tanks at Hanford contain most of the actinides as well as non-radioactive materials. Among these materials, aluminum oxide is particularly problematic to the vitrification of high-level waste sludges because it is present in large amounts and it is not as easily removed from the sludge by baseline leaching processes. Our earlier exploratory leaching studies with sludge simulants indicated that HEDPA could assist with the dissolution of Al-oxides. Furthermore, interactions of actinides with aluminum oxide have significant implications in designing the strategies for sludge leaching. Therefore, we have begun to examine the behavior of actinides in the leaching of aluminum oxide with HEDPA, a complexant that forms strong complexes with actinides and aluminum in acidic to basic solutions.

Batch adsorption/dissolution experiments were first conducted to examine the effect of HEDPA on the dissolution of aluminum oxyhydroxide boehmite $(\gamma$-AlOOH) in $1.0 \mathrm{M} \mathrm{NaCl}$. As shown by Figure 3, in the $\mathrm{pH}$ range 4 to 9 , complexation of Al by HEDPA significantly enhanced dissolution of boehmite. This phenomenon was especially pronounced in the neutral $\mathrm{pH}$ region where the solubility of aluminum is limited by the formation of sparsely soluble aluminum hydroxides. At higher $\mathrm{pH}$, dissolution of boehmite appears to be slightly inhibited by HEDPA. , Both enhancement and inhibition of boehmite dissolution are assumed to be due to differing modes of coordination between HEDPA and the boehmite surface. To help understand the interactions between HEDPA and aluminum oxyhydroxide, the Al(III)/HEDPA complexes in solutions are being characterized by thermodynamic (potentiometry and calorimetry) and spectroscopic techniques $\left({ }^{31} \mathrm{P}\right.$ and $\left.{ }^{27} \mathrm{Al} \mathrm{NMR}\right)$.

Batch experiments have been started to examine the sorption/desorption of ${ }^{233} \mathrm{U}(\mathrm{VI})$ on aluminum oxyhydroxide boehmite in the absence and presence of HEDPA. The results will be presented in the progress report for the next reporting period. 


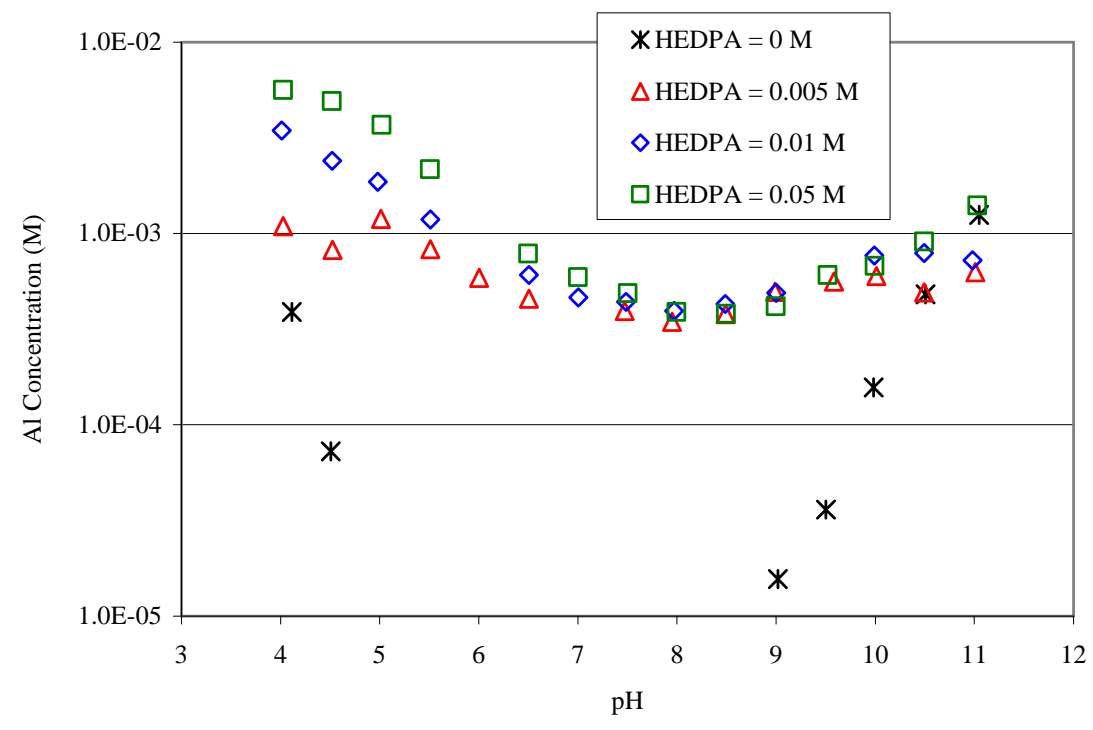

Figure 3: Effect of HEDPA on boehmite dissolution after 86 days (1.0 M NaCl; $0.01 \mathrm{M}\left(0.60 \mathrm{~g} \mathrm{~L}^{-1}\right)$ boehmite)

\section{Uranyl Gluconate Chemistry}

To complete the remediation of the Hanford tank sludges, alkaline leaching strategies are being developed, principally to remove problematic non-radioactive components like Al, $\mathrm{Cr}, \mathrm{S}$, and P. Recently, the suggestion has been made that organic complexants could be employed for selective leaching of these species to enhance removal of matrix metal ions. One reagent that has been identified, gluconate $\left(\mathrm{O}_{2} \mathrm{C}-(\mathrm{CHOH})_{4} \mathrm{CH}_{2} \mathrm{OH}\right)$, is of particular interest because it is known to strongly complex metal ions in alkaline solutions. Gluconate also is believed to be present in some wastes as a by-product of process application or of cellulose degradation. Though it is well known that polyvalent metal ions interact with gluconate, little information is available on the interactions of actinides with this ligand at high $\mathrm{pH}$, ionic strength and temperature. The work presented here describes early results of an investigation into the coordination chemistry $\mathrm{UO}_{2}{ }^{2+}$ in relevant media. Selected highlights of this continuing work are described as follows:

- It has been suggested in the literature that the alcoholic protons in gluconate have measurable Brönsted acidity and thus can be readily lost from gluconate upon complexation. An investigation by ${ }^{13} \mathrm{C}$ NMR did not provide any compelling evidence for deprotonation of the alcoholic protons upon addition of up to 4.5 equivalents of base in samples containing only gluconate. This result implies that the alcoholic groups have $\mathrm{pK}_{\mathrm{a}}$ 's above 13. Similar NMR spectroscopic experiments with uranyl gluconates are planned.

- Potentiometric titrations (Figure 4) have been done to characterize the equilibria describing the complexation of uranyl by gluconate over the $\mathrm{pH}$ range of 3-12. The

\begin{tabular}{|l|}
\hline Deleted: uranyl \\
\hline Deleted: gluconate \\
\hline Deleted: chemistry \\
\hline
\end{tabular}


best fit of the potentiometric titration data required the presence of six species of the general stoichiometry $\left[\left(\mathrm{UO}_{2}\right)_{1-2}(\mathrm{OH})_{2-5}(\mathrm{Gluc})_{1}\right]^{-2-0}$.

- Complex formation constants are reported as overall constants and are defined by the below equation and tabulated in Table 1 .

$$
\beta_{m h l}=\frac{\left[\left(U O_{2}^{2+}\right)_{m}(\mathrm{OH})_{h} L_{l}\right]\left[H^{+}\right]^{h}}{\left[U O_{2}^{2+}\right]^{m}[L]^{l}}
$$

- Spectroscopic studies are underway to elucidate the most probable modes of coordination of the uranyl cation with gluconate, specifically to address whether alcoholic oxygen atoms of gluconate or the waters of solvation lose hydrogen ions to the solution to account for the stoiochiometries indicated in the table.
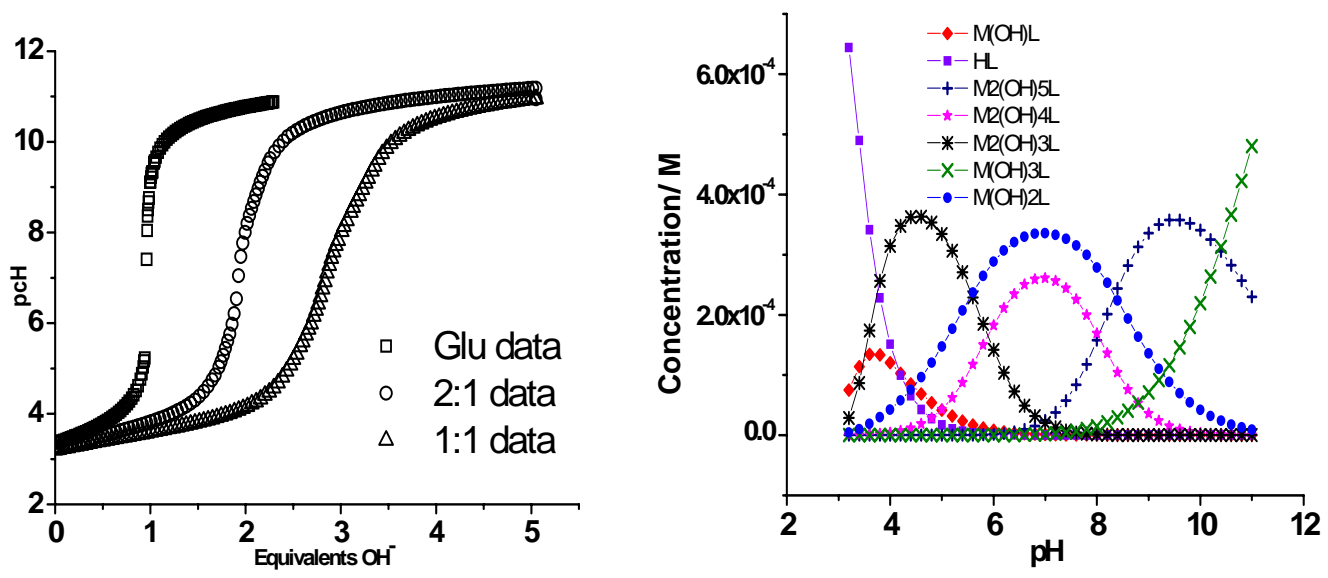

Figure 4 a. pH titrations of sodium gluconate, a 2:1 mixture of Glu: $U$ and a 1:1 mixture of Glu: $U$ ([Glu $]_{\text {init }}=0.001 \mathrm{M}$ in each), $\mathbf{4 b}$. Calculated speciation of uranyl gluconate at $\left[\mathrm{UO}_{2}{ }^{2+}\right]=$ $\left[\mathrm{NaGluc}_{t}=0.001 \mathrm{M}\right.$.

The predominance of species having the general stoichiometry $\left(\mathrm{UO}_{2}\right)_{2}(\mathrm{OH})_{3-5}$ gluc, that is multiple metal cations bound to a single ligand with only a single obvious chelation site (the $\alpha$ hydroxycarboxylate end of the molecule), is the most notable feature of the system. Calorimetry experiments and spectroscopic studies are in progress to attempt to provide additional insight into the question of the coordination chemistry of these complexes. 
Table 1 Stability constants of $\mathrm{UO}_{2}{ }^{2+}$ with

Gluconate for the complex $\left(\mathrm{UO}_{2}{ }^{2+}\right)_{m}(\mathrm{H})_{h}(\mathrm{~L})_{l}$

$\left(\mathrm{I}=0.1\left(\mathrm{NaClO}_{4}\right), 25 \mathrm{C}\right)$.

\begin{tabular}{ccc}
\hline $\begin{array}{c}\text { Stoichiometry } \\
m h l\end{array}$ & $\log \beta_{m h l}$ & $\pm \mathrm{l} \sigma$ \\
\hline $1,-1,1$ & -0.63 & 0.07 \\
$1,-2,1$ & -5.08 & 0.03 \\
$1,-3,1$ & -14.36 & 0.03 \\
$2,-3,1$ & -4.35 & 0.03 \\
$2,-4,1$ & -10.24 & 0.05 \\
$2,-5,1$ & -18.27 & 0.04 \\
\hline
\end{tabular}

\section{Cleanup of Aluminum Nitrate Solution by Solvent Extraction}

Operational experience with actual sludge samples and simulants has established that aluminum removal by a straight-forward leaching with concentrated alkali achieves inconsistent degrees of success. Our previous exploratory leaching studies suggest that contact of sludges (leached first with concentrated alkali) release substantially larger amounts of Al when a follow-on contact with dilute acid is applied. Application of acidic leachants for enhancing $\mathrm{Al}$ removal could improve $\mathrm{Al}$ waste management, but might at the same time encourage the release of additional TRUs from the sludge. Starting from the premise that a dilute acid leach would not necessarily dramatically increase the volume of secondary wastes produced, it would be possible to apply standard methods of hydrometallurgy to remove TRU's from the resulting slightly acidic $\mathrm{Al}\left(\mathrm{NO}_{3}\right)_{3}$ leachates produced. The work presented below describes the results of a continuing investigation into the removal of $\mathrm{U}(\mathrm{VI})$ from dilute acid solutions containing high concentrations of $\mathrm{Al}(\mathrm{III})$ and $\mathrm{Cr}(\mathrm{VI})$ using conventional solvent extraction with tri-n-butyl phosphate (TBP). To date, we have observed that:

- $30 \%$ TBP in dodecane will effectively remove $\mathrm{U}$ from solutions containing high concentrations of $\mathrm{Al}\left(\mathrm{NO}_{3}\right)_{3}$, millimolar chromate and dilute nitric acid. Back extraction of the uranium is also readily accomplished by contact with dilute nitric acid, the level of decontamination is such that the $\mathrm{Al}\left(\mathrm{NO}_{3}\right)_{3}$ would be considered low-level wastes at worst.

- Chromium(VI) exhibits some tendency to partition into the organic phase in the absence of $\mathrm{U}(\mathrm{VI})$, a greater tendency to partition when $\mathrm{U}(\mathrm{VI})$ is present, and under some conditions resistance to back extraction. Contact of the organic solution containing chromate with a reducing agent results in the removal of most of the chromate from the organic phase if enough time for contact is allowed.

- At higher concentrations and moderate levels of acidity, $\mathrm{Cr}(\mathrm{VI})$ is reduced in the presence of TBP. We have hypothesized that incomplete back extraction of $\mathrm{Cr}$ may weel be the result of retention of $\mathrm{Cr}(\mathrm{III})$ species in the organic phase. Other studies indicate that $\mathrm{Cr}\left(\mathrm{NO}_{3}\right)_{3}$ is at best weakly extracted by $30 \% \mathrm{TBP}$, suggesting some hysteresis in the solvent extraction. At higher nitric acid concentrations, we have seen evidence for 
interfacial redox reactions. It appears that pre-application of a water soluble reducing agent accomplishes $\mathrm{Cr}(\mathrm{VI})-\mathrm{Cr}(\mathrm{III})$ reduction and a cleaner separation of $\mathrm{U}(\mathrm{VI})$ from the $\mathrm{Al}\left(\mathrm{NO}_{3}\right)_{3}$ solution.

Work continues on each of these aspects. Plans include profiling of $\mathrm{Am}^{3+}, \mathrm{Eu}^{3+}$ and Pu solvent extraction performance in this system.

\section{Anion Control in Final Processing Effluents}

The efficiency of vitrification processes and the volume of wastes that will ultimately be produced are significantly impacted by the large amounts of $\mathrm{Al}$ present and by the small amounts of $\mathrm{SO}_{4}{ }^{\circ}, \mathrm{CrO}_{4}{ }^{=}$, and $\mathrm{PO}_{4}{ }^{3-}$ that are present in slurry feeds to the vitrifiers. Greater control of the transport of these species will enable the creation of more robust waste forms and more efficient processes for glass making. Preliminary work has been completed to establish the efficacy of heavy metal precipitation for anion control in sludge leachates. The objective of this aspect of our program is to precipitate these anions by addition of $\mathrm{Ba}^{2+}, \mathrm{Pb}^{2+}, \mathrm{Cd}^{2+}$, (for $\mathrm{SO}_{4}{ }^{{ }^{2}}$ and $\mathrm{CrO}_{4}{ }^{{ }}$) or $\mathrm{Ln}^{3+}, \mathrm{Fe}^{3+}$ (for $\mathrm{PO}_{4}^{3-}$ ) solids for disposal as low-level wastes containing minimal radioactivity. Early results include non-rad scoping experiments in which small volumes of dilute $\mathrm{BaCl}_{2}$ is mixed with dilute solutions of $\mathrm{Na}_{2} \mathrm{SO}_{4}, \mathrm{Na}_{2} \mathrm{CrO}_{4}$, or $\mathrm{Na}_{3} \mathrm{PO}_{4}$ as a function of $\mathrm{pH}$ followed by gravimetric analysis of the precipitates, and 24 hour precipitation and sorption experiments with ${ }^{152,154} \mathrm{Eu}$ tracer (as a model for $\mathrm{An}^{3+}$ ). As shown in Figure 2, the expected near quantitative precipitation of $\mathrm{BaCrO}_{4}$ and $\mathrm{BaSO}_{4}$ effectively quantitatively removes these anions from dilute solutions over a wide range of $\mathrm{pH}$, while $\mathrm{Ba}^{2+}$ has more limited success in controlling phosphate solubility. Eu sorption onto and removal from (or incorporation into) the solids is a complex function of conditions. These preliminary results establish the basic validity of the concept. More work is needed and planned.

Figure 5. Precipitation of $\mathrm{SO}_{4}{ }^{ }$, $\mathrm{CrO}_{4}{ }{ }$, and $\mathrm{PO}_{4}{ }^{3-}$ upon Addition of $\mathrm{BaCl}_{2}$ Solutions.

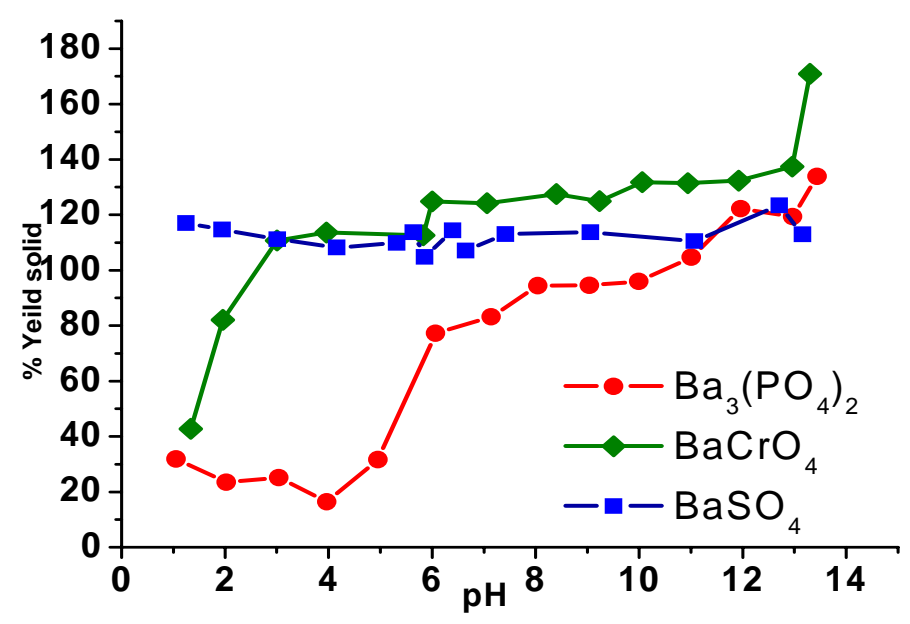




\section{PLANNED ACTIVITIES}

While continuing the studies of the sorption of $\mathrm{U}(\mathrm{VI})$ on alumina in the presence of HEDPA, comparative studies with other actinides (e.g., $\mathrm{Pu}(\mathrm{VI})$ and $\mathrm{Np}(\mathrm{V})$ ) and lanthanides (e.g., $\mathrm{Eu}(\mathrm{III})$ ) will be started in FY06. Manuscripts on the thermodynamic and kinetic studies of the complexation between $\mathrm{U}(\mathrm{VI})$ and diphosphonic acids will be prepared. We are also planning further investigations of the aluminum complexes with HEDPA and with gluconate. Additional solvent extraction experiments will be done examining the efficacy of solvent extraction cleanup of $\mathrm{Al}\left(\mathrm{NO}_{3}\right)_{3}$ and the partitioning of TRUs plus chromium in this system. Our investigations of actinide gluconates will continue on toward studies of the characteristics of oxidized $\mathrm{Np}$ and $\mathrm{Pu}$ species. We will continue to emphasize fundamental studies of the thermodynamics and kinetics of pertinent reactions, while investing additional effort in the application of spectroscopic techniques for the definition of the coordination chemistry of the systems. We have also established a working relationship with researchers at BNG Americas to provide advice and assistance on the development of aluminum leaching procedures for potential application. Finally, we have numerous additional publications on aluminum leaching and gluconate characterization in progress.

\section{INFORMATION ACCESS}

\section{Journal Articles}

Oxidative Alkaline Leaching of Americium from Simulated High-Level Waste Sludges W. A. Reed, A. Yu. Garnov, L. Rao, K. L. Nash, A. H. Bond, Separations Science and Technology, 40 (5), 1029-1046 (2005).

Oxidative Leaching of Plutonium from Simulated Hanford Tank-Waste Sludges Kenneth L. Nash, Marian Borkowski, Melissa Hancock, and Ivan Laszak, Separation Science and Technology, 40, 1497-1512 (2005).

Kinetics of the Reaction of U(VI ) with Benzene-1,2-diphosphonic Acid H. Hall, J.C. Sullivan, P.G. Rickert, K.L. Nash, Dalton Trans. 2011-2016 (2005).

Alkaline Sequestrants in Hanford Tank Waste Processing L. R. Martin, R. L. P. Witty and K. L. Nash, Actinides 2005 proceedings, in press

Anion Control in Hanford Leachates by Solid-Liquid Separation

L. R. Martin, A. R. Routt, R. M. Olsen and K. L. Nash, Actinides 2005 proceedings, in press

Uranium Removal from Process Effluents Containing Chromate and Aluminum Nitrate L. R. Martin, R. C. Harrington, J. J. Neeway and K. L. Nash, Actinides 2005 proceedings, in press

Thermodynamics of the Complexation of U(VI) with Hydroxyethane-1,1-diphosphonic Acid in Acidic to Basic Solutions 
W. A. Reed, L. Rao, P. Zanonato, K. L. Nash, , manuscript in preparation.

A Kinetic Study of the Complexation of U(VI) with Diphosphonic Acids

W. A. Reed, L. Rao, K. L. Nash, manuscript in preparation.

\section{Presentations}

Characterization of actinides during HEDPA leaching for aluminum dissolution in tank waste sludges, B. Powell, L. Rao, K. L. Nash, L. Martin, submitted to Materials Research Society 2005 Fall Meeting, Boston, November, 2005.

New (and Old) Approaches to Cleanup of Hanford Sludge Leachate Solutions, Leigh R. Martin, $29^{\text {th }}$ Actinide Separations Conference, Nashville, TN, May 2005, Oral presentation

Alkaline Sequestrants in Hanford Tank Waste Processing

L. R. Martin, R. L. P. Witty and K. L. Nash, Actinides 2005, Manchester, England, poster presentation

Anion Control in Hanford Leachates by Solid-Liquid Separation

L. R. Martin, A. R. Routt, R. M. Olsen and K. L. Nash, Actinides 2005, Manchester,

England, poster presentation

Uranium Removal from Process Effluents Containing Chromate and Aluminum Nitrate

L. R. Martin, R. C. Harrington, J. J. Neeway and K. L. Nash, Actinides 2005,

Manchester, England, poster presentation

Kinetics and Mechanism of Actinide Complexation by Polydentate Ligands,

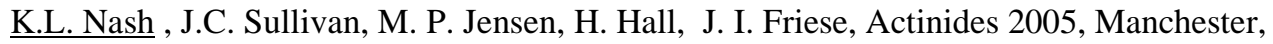
England, poster presentation

New (and Old) Approaches to Cleanup of Hanford Sludge Leachate Solutions,

L. R. Martin, M. Routt, R. Olsen, J. Neeway, K. L. Nash, EMSP symposium, American

Chemical Society meeting, Washington DC, August, 2005, oral presentation

Actinides in alkaline oxidizing media: species relevant to tank waste pretreatment,

Kenneth L. Nash, Leigh R. Martin, Ryan Witty, Linfeng Rao, Wendy Reed, Brian

Powell, EMSP symposium, American Chemical Society meeting, Washington DC,

August, 2005, oral presentation 